\title{
Synthesis of heteroaromatic 3,3'-bridged biscarbenes of the 1,2,4-triazole series and their properties
}

\author{
Artyom V. Kiselyov, ${ }^{\text {a }}$ Nikolai I. Korotkikh,*a Alan H. Cowley, ${ }^{* b}$ Jennifer A. Moore, \\ Michael A. Findlater, ${ }^{b}$ Tatyana M. Pekhtereva, ${ }^{a}$ and Oles P. Shvaika ${ }^{c}$ \\ ${ }^{a}$ The L. M. Litvinenko Institute of Physical Organic and Coal Chemistry, Ukrainian \\ Academy of Sciences, 70, R. Luxemburg, Donetsk, 83114, Ukraine \\ ${ }^{b}$ The University of Texas at Austin, Department of Chemistry \& Biochemistry, 1 \\ University Station A5300, Austin, Texas 78712-0165, USA \\ ${ }^{c}$ Donetsk National University, 24, Universitetskaya, Donetsk, 83055, Ukraine \\ E-mail:nkorotkikh@ua.fm, cowley@mail.utexas.edu
}

\begin{abstract}
The stable 3,3'-bridged biscarbenes, 1,4- and 1,3-bis[1-alkyl-4-phenyl-1,2,4-triazol-5-yliden-3yl]benzenes (5a,b,d) and 1,3-bis[1-(1-adamantyl)-4-phenyl-1,2,4-triazol-5-yliden-3-yl]butane (5c) have been prepared. Treatment of $\mathbf{5 b}$ with copper (I) chloride in tetrahydrofuran/acetonitrile solution and cobalt (II) chloride in acetonitrile or acetonitrile/toluene solution afforded the biscarbene copper (I) complex 8. The reactions of 5d with diphenyldiazomethane and sulfur resulted in the novel bisthione 6 and bisazine (7) derivatives, respectively. The X-ray crystal structures of $\mathbf{5 d}, \mathbf{8}$ were determined.
\end{abstract}

Keywords: Biscarbenes, 1,2,4-triazoles, copper complexes

\section{Introduction}

Stable polycarbenes have not been studied extensively thus far. For example, Dias and Jin ${ }^{1}$ have described the synthesis of mesitylene-2,4,6-tris(methyl-1-imidazol-2-ylidene). However, the Xray crystal structure has not yet been reported. Bisimidazol-2-ylidenes which are linked via nitrogen atoms and an aliphatic bridge have been used for the in situ chelation of metal cations. ${ }^{2}$ Bisimidazol-2-ylidenes featuring a pyridine ring have also been described $^{3,4}$ and used for the preparation of carbene chelated complexes. However, stable carbenes of the 1,2,4-triazole series with conjugated bonds between the carbene moieties were unknown until recently. ${ }^{5}$ Such compounds exhibit high kinetic stabilities that are comparable to those of their mononuclear analogues. Accordingly, bistriazolylidenes represent promising targets for the creation of conjugated polymers and nanostructures, ligands for metal catalysts, and catalysts for organic 
reactions. Recently, we have reported the syntheses of 4,4'-bridged bis-1,2,4-triazol-5-ylidenes with conjugated structures. ${ }^{6}$

In the present contribution we describe (i) the synthesis of four 3,3'-bridged bis-1,2,4-triazol5-ylidenes 5a-d, including those with conjugated structures, 5a,b,d; (ii) the preparation of the copper (I) carbene complexe 8 supported by the 1,3-bis-(1-adamantyl-4-phenyl-1,2,4-triazol-5yliden-3-yl)benzene ligand $\mathbf{5 b}$, (iii) adducts of the biscarbene $\mathbf{5 d}$ with sulfur (6) and diphenyldiazomethane (7); (iv) the single crystal X-ray structure of 1,4-bis-(1-tert-butyl-4phenyl-1,2,4-triazol-5-yliden-3-yl)benzene 5d and (v) the complex of 1,3-bis-(1-adamantyl-4phenyl-1,2,4-triazol-5-yliden-3-yl)benzene with copper (I) chloride (8).

\section{Results and Discussion}

The syntheses of biscarbenes of the 1,2,4-triazole series were carried out in three steps: (1) the bis-1,2,4-triazoles 2a-c were obtained by ring transformations of the bis-1,3,4-oxadiazoles 1a-c with anilines; (2) subsequent quaternization of the 1,2,4-triazoles 2a-c with 1-bromoadamantane or tert-butyl iodide afforded the bis-1,2,4-triazolium salts 3a-d; (3) finally, the bis-1,2,4-triazol5-ylidenes 5a-d were prepared by deprotonation of salts 3a-d by treatment with bases. The first stage of the process has already been described ${ }^{7}$ and involves the ring transformation of arylenbis-1,3,4-oxadiazoles 1a,b and butylen-bis-1,3,4-oxadiazole 1c with aniline trifluoroacetate in odichlorobenzene at $200{ }^{\circ} \mathrm{C}$ thus affording bistriazoles 2a-c. In the absence of acids this reaction is slow and accompanied by contamination of the product with colored impurities. However, in the presence of trifluoroacetic acid the colored impurities are not observed and reaction yields of up to $95 \%$ of the bistriazole $\mathbf{2 a}$ were obtained. The isolated yield of triazole $\mathbf{2 b}$ is lower $(46 \%)$ than that of $2 \mathbf{a}(95 \%)$ due to washing of the product with aqueous alkalis. In the case of the ring transformation of 1,4-butylen-bis-1,3,4-oxadiazole with p-bromoaniline the yield of bistriazole 2c was markedly reduced $(27 \%)$. This is probably due to the various nucleophilic transformations of the system. Similar observations have been reported for aliphatic derivatives of 1,3,4-oxadiazoles. ${ }^{8}$ The use of aniline hydrochloride or hydrobromide gives similar results. However in this methodology it is the sublimation of the aniline salts that is responsible for decreased yields. In the present method the use of the polar solvent o-dichlorobenzene (2.50 D), was effective in terms of providing a high reaction rate due to azeotropic removal of water from the reaction mixture at the process temperature.

The second stage of the process is the quaternization of bistriazoles 2a-c by treatment with 1bromoadamantane, tert-butyl iodide, or benzyl chloride. These reactions proceed efficiently in acetic acid, ${ }^{5,9}$ thus allowing decreased base-promoted elimination of hydrogen halide from the alkylating agent. ${ }^{10}$

The use of 1-adamantyl- or tert-butyl halides for the quaternization reaction serves two purposes. First, it is known that these substituents provide steric protection of the carbene center. This strategy has been used for the synthesis of stable heteroaromatic carbenes of the imidazole 
and benzimidazole series. ${ }^{11-13}$ In the present work it was observed that triazole quaternization with the indicated tertiary alkyl reagents resulted in the exclusive formation of the 1-isomeric salts. On the other hand, NMR studies indicate that primary alkylating reagents such as dimethylsulfate and benzyl chloride give mixtures of the isomeric 1- or 2-substituted salts in which the 1-isomers predominate. However, it was found that the benzyl substituted salt 3e contains mainly the 1-isomer after recrystallization.

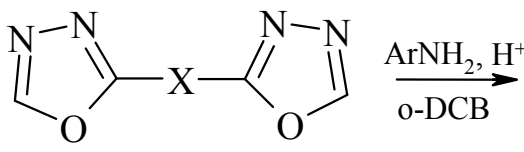

1 a-c

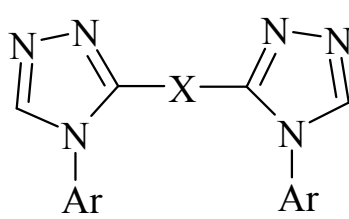

2 a-c

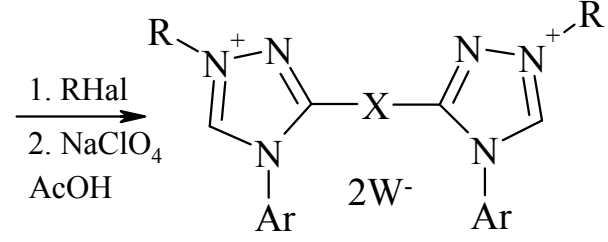

3 a-e

$1 \mathrm{X}=p-\mathrm{C}_{6} \mathrm{H}_{4}$ (a), $m-\mathrm{C}_{6} \mathrm{H}_{4}(\mathbf{b}),\left(\mathrm{CH}_{2}\right)_{4}(\mathbf{c}) ; 2 \mathrm{X}=p-\mathrm{C}_{6} \mathrm{H}_{4}, \mathrm{Ar}=\mathrm{Ph}(\mathbf{a}), \mathrm{X}=m-\mathrm{C}_{6} \mathrm{H}_{4}, \mathrm{Ar}=\mathrm{Ph}(\mathbf{b}), \mathrm{X}$ $=\left(\mathrm{CH}_{2}\right)_{4}, \mathrm{Ar}=p-\mathrm{BrC}_{6} \mathrm{H}_{4}(\mathbf{c}) ; 3 \mathrm{R}=\mathrm{Ad}, \mathrm{X}=p-\mathrm{C}_{6} \mathrm{H}_{4}, \mathrm{Ar}=\mathrm{Ph}, \mathrm{W}=\mathrm{Br}(\mathbf{a}), \mathrm{R}=\mathrm{Ad}, \mathrm{X}=m-\mathrm{C}_{6} \mathrm{H}_{4}, \mathrm{Ar}=$ $\mathrm{Ph}, \mathrm{W}=\mathrm{ClO}_{4}(\mathbf{b}), \mathrm{R}=\mathrm{Ad}, \mathrm{X}=\left(\mathrm{CH}_{2}\right)_{4}, \mathrm{Ar}=p-\mathrm{BrC}_{6} \mathrm{H}_{4}(\mathbf{c}), \mathrm{R}=t-\mathrm{Bu}, \mathrm{X}=p-\mathrm{C}_{6} \mathrm{H}_{4}, \mathrm{Ar}=\mathrm{Ph}, \mathrm{W}=\mathrm{ClO}_{4}$ (d), $\mathrm{R}=\mathrm{Bn}, \mathrm{X}=p-\mathrm{C}_{6} \mathrm{H}_{4}, \mathrm{Ar}=\mathrm{Ph}, \mathrm{W}=\mathrm{ClO}_{4}(\mathbf{e})$.

\section{Scheme 1}

The compositions and structures of compounds $\mathbf{2 a - c}$ and 3a-d were established on the basis of elemental analyses and ${ }^{1} \mathrm{H}$ NMR spectroscopy. Product purities were estimated by NMR spectroscopy and thin layer chromatography (TLC). The ${ }^{1} \mathrm{H}$ NMR spectra of these compounds feature signals for the aromatic protons $\mathrm{CHN}$ in the range $\delta 8.3-9.0 \mathrm{ppm}$ and the protons for the benzene nuclei resonate in the range $\delta 7.1-8.4 \mathrm{ppm}$. It is interesting to note that the signals for the CHN protons of bistriazoles $\mathbf{2 a , b}$ are significantly downfield relative to those of the monotriazoles by $\Delta \delta 0.5-0.7 \mathrm{ppm}$. This observation is presumably due to conjugation of the triazole and phenylene rings in the bistriazole molecules discussed above. Support for this conclusion stems from the weak influence of the triazole rings in bistriazole $2 \mathbf{c}$ with respect to the resonance of the CHN protons observed at $\delta 8.17 \mathrm{ppm}$. In the cases of compounds 3a-e the CHN proton signals also fall in the characteristic range of $\delta 10.4-10.8 \mathrm{ppm}$.

The syntheses of the carbenes were effected by deprotonation of the corresponding bistriazolium salts 3a-d under the action of potassium tert-butoxide or hexamethyldisilazanide in toluene solution or by treatment with sodium hydride in acetonitrile solution (Scheme 2) according to the procedures described for the analogous mononuclear and binuclear derivatives. ${ }^{11-14}$ Note, however, that $\mathbf{3 e}$ forms colored ylidic compounds and does not produce a carbene. In the case of biscarbene $\mathbf{5 a}$, the procedure was modified in order to increase the reaction selectivity and enhance the yield. The reaction of potassium tert-butoxide with bistriazolium salt 3a in toluene solution (Procedure A) leads to high overall yields (up to $100 \%$ ) of unpurified product 5a that features significant quantities of impurities that are insoluble in 
aromatic solvents (up to $30 \%$ ). The use of potassium hexamethylsilazanide (Procedure B) affords carbene 5a in good yield (65\%) and is suitable for use for subsequent synthesis without additional purification.

However, the best result was achieved by conducting the deprotonation of salt 3a with potassium tert-butoxide in a toluene-methanol solvent mixture (Procedure C). ${ }^{5,14}$ In this case the initially isolated products are methoxyazolines 4 which are formed by methanol addition to the carbenes. However, compounds $\mathbf{4}$ are readily converted into the corresponding carbenes by heating in vacuum. This approach is reminiscent of the Enders' method. ${ }^{15}$ However, in this case, namely in the presence of sodium methoxide and the absence of toluene, the reaction does not proceed to completion. Furthermore, the decomposition of the azoline in the present procedure is effected very easily and does not require several hours of heating in vacuo. In the present case the yield of biscarbene $\mathbf{5 a}$ is $85 \%$ and the product purity is high.

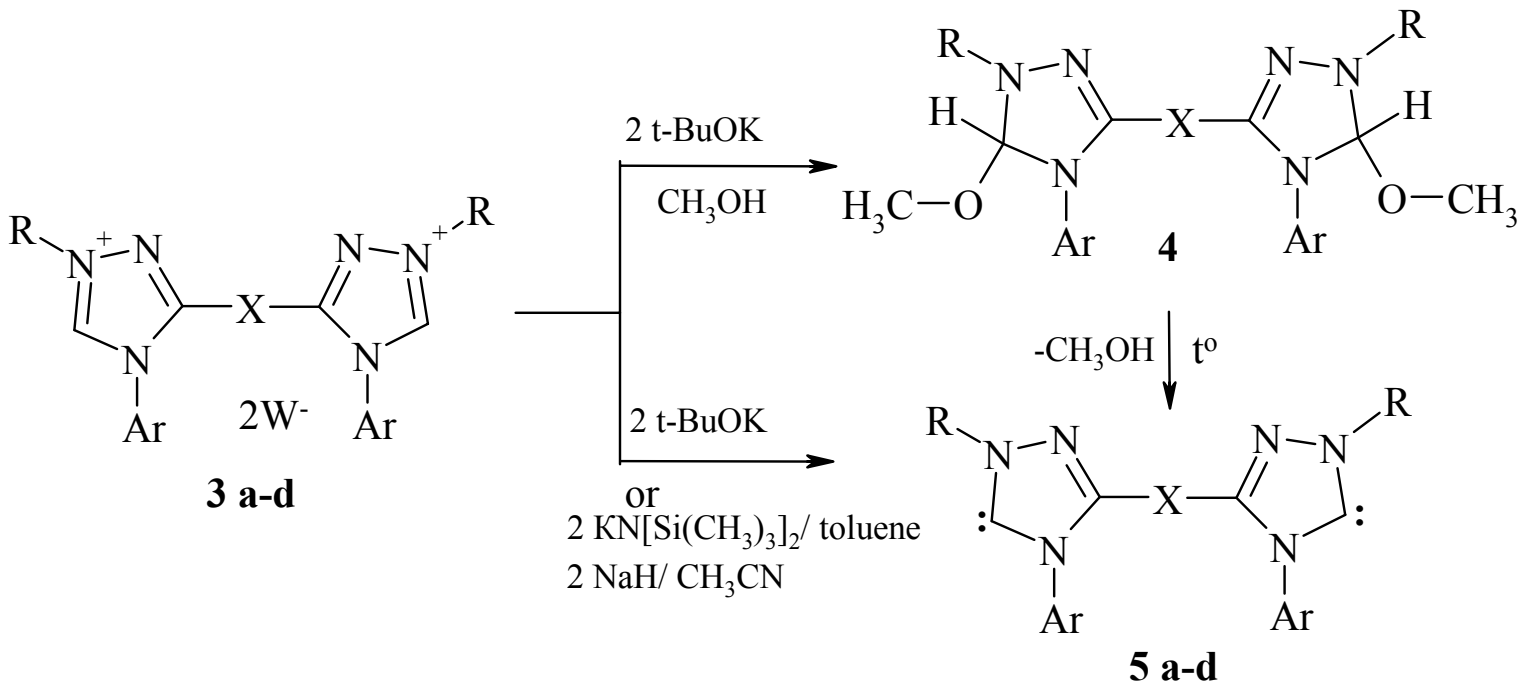

$5 \mathrm{X}=p-\mathrm{C}_{6} \mathrm{H}_{4}, \mathrm{R}=\mathrm{Ad}, \mathrm{Ar}=\mathrm{Ph}(\mathbf{a}) ; \mathrm{X}=m-\mathrm{C}_{6} \mathrm{H}_{4}, \mathrm{R}=\mathrm{Ad}, \mathrm{Ar}=\mathrm{Ph}(\mathbf{b}) ; \mathrm{X}=\left(\mathrm{CH}_{2}\right)_{4}, \mathrm{R}=\mathrm{Ad}, \mathrm{Ar}=$ $p-\mathrm{BrC}_{6} \mathrm{H}_{4}(\mathbf{c}) ; \mathrm{X}=p-\mathrm{C}_{6} \mathrm{H}_{4}, \mathrm{R}=t-\mathrm{Bu}, \mathrm{Ar}=\mathrm{Ph}(\mathbf{d})$.

Scheme 2

The preparation of the isomeric biscarbene 1,3-bis(1-adamantyl-4-phenyl-1,2,4-triazol-5yliden-3-yl)benzene $\mathbf{5 b}$ from the corresponding salt by treatment with potassium tert-butoxide in toluene solution (Procedure A) results in a $64 \%$ yield of a product that is contaminated with the corresponding bisazolium tert-butoxide. However, because triazolium salt $\mathbf{3 b}$ is considerably more soluble in organic solvents than $\mathbf{3 a}$ it seemed appropriate to employ a different method of deprotonation. Indeed, the use of sodium hydride in acetonitrile solution (Procedure D) 5,14 resulted in samples of the biscarbene that were precipitated from the reaction mixture. The ratio of the solubilities of salts $\mathbf{3 a}$ and $\mathbf{3 b}$ is close to that for the biscarbenes. However, in contrast to the $p$-isomer $\mathbf{5 a}$, the $m$-phenylenbiscarbene $\mathbf{5 b}$ is not only more soluble in aromatic solvents, but 
also soluble in saturated hydrocarbons. Carbene $\mathbf{5 d}$ was also prepared by method D due to the higher solubility of the precursor salt $\mathbf{3} \mathbf{d}$ in acetonitrile.

Compound 5c was prepared in order to study the influence of the phenylene bridge on the stability of biscarbenes. In this case the carbene moieties are separated by an aliphatic bridge comprising four carbon atoms. Deprotonation of the precursor was effected by treatment with potassium tert-butoxide in toluene solution (Procedure A) and the desired product was isolated in $77 \%$ yield.

The ${ }^{1} \mathrm{H}$ NMR spectra of compounds 5a-d include the resonances for the adamantyl (5a-c), tert-butyl (5d) and aromatic protons. No signals were detected for the hydrolysis products of the carbenes (formyldiamines and azolium hydroxides) thus confirming the anhydrous nature of the reaction conditions. The adamantyl methylene resonances for the protons closest to the nitrogen atoms of carbenes 5a-c are downfield shifted ( $\delta 2.57-2.62 \mathrm{ppm})$ with respect to other signals for this group and even for bis-cation salts 3a-c $(\delta 2.24-2.29 \mathrm{ppm})$ that feature typical electron withdrawing ring systems. Similar chemical shift values have not been observed for other adamantyl proton signals of carbenes: they are typically upfield relative to those of the bis-cation salt resonances $(\Delta \delta 0.1-0.3 \mathrm{ppm})$. Presumably, the adamantyl protons are deshielded because of their proximity to the carbene electron pair. A similar observation has been made in the case of monocarbenes of the 1,2,4-triazole series. ${ }^{14}$ The most important NMR spectral feature of biscarbenes 5a-d is the characteristic ${ }^{13} \mathrm{C}$ resonance of the carbene carbon, which is observed in the range $\delta 203-208 \mathrm{ppm}$. In the case of biscarbene 5d $(\mathrm{R}=$ tert-butyl) this resonance is upfield ( $\delta 203$ ppm) relative to those of biscarbenes 5a-c $(\mathrm{R}=1-\mathrm{Ad}, \delta 207 \mathrm{ppm}, 207 \mathrm{ppm}$ and $208 \mathrm{ppm}$, respectively) and monocarbenes of the triazole series ( $\delta 210-214 \mathrm{ppm}$ ). ${ }^{12-14}$ This trend is attributable to increased conjugation due to the presence of an aromatic bridge. The IR spectrum of biscarbene 5a provided no evidence for the presence of hydrolysis products.

Biscarbenes 5a-d are stable compounds that are unchanged upon storage for several months in the absence of moisture and oxygen. This distinguishes them from some other biscarbene systems that tend to undergo dimerization. ${ }^{16}$ In fact, crystalline samples of biscarbenes 5a-d undergo little change after several days of exposure to the atmosphere.

Crystals of biscarbene 5d suitable for X-ray diffraction study were grown from a 1:1 toluenetetrahydrofuran solution. To analyze the structure we used not only the metrical parameters of the molecule (bond lengths and angles) but also the bond orders calculated using the linear dependence of bond lengths and bond orders $(p)$ in model compounds (ethane $\mathrm{C}-\mathrm{C}, 1.534 \mathrm{~A}$; ethylene $\mathrm{C}=\mathrm{C}, 1.337 \mathrm{~A}$; methylamine $\mathrm{C}-\mathrm{N}, 1.474 \mathrm{~A}$; methylenimine $\mathrm{C}=\mathrm{N}, 1.300$ A; hydrazine $\mathrm{N}$ $\mathrm{N}, 1.449$ A and azomethane $\mathrm{N}=\mathrm{N}, 1.254 \mathrm{~A}$ ) (Figure 1, Table 1) in a similar fashion to that described previously. ${ }^{6}$ For comparison of the X-ray data one mononuclear carbene 1-tert-butyl3-phenyl-4-(4-bromophenyl)-1,2,4-triazol-5-ylidene A was also used, as described in reference 17. The molecular structure of $\mathbf{5 d}$ features an overall trans conformation and the phenylene link is twisted by $30^{\circ}$ with respect to the triazole rings. The bond order between the carbene nucleus and the central phenylene link is $p 1.310$. The N(4)-phenyl nucleus is twisted by $59^{\circ}$ thus decreasing the bond order to $p$ 1.190. The inner angle at the carbene carbon atom $\left(100.4^{\circ}\right)$ is in agreement 
with the data for an analogous mononuclear carbene with a tert-butyl group. ${ }^{17} \mathrm{The} \mathrm{C}(5)-\mathrm{N}(1)$ bond order in the triazole ring is 1.753 (cf., for the mononuclear analogue $\mathbf{A}, p$ is 1.799). The other cyclic bonds have bond orders that are similar to those for mononuclear analogues $-\mathrm{C}(5)-\mathrm{N}(4)-$ 1.511, $\mathrm{C}(3)-\mathrm{N}(4)-1.523$, multiple bond $\mathrm{C}(3)=\mathrm{N}(2) 1.977$ (for $\mathbf{A}-1.494,1.546$ and 1.966, respectively).

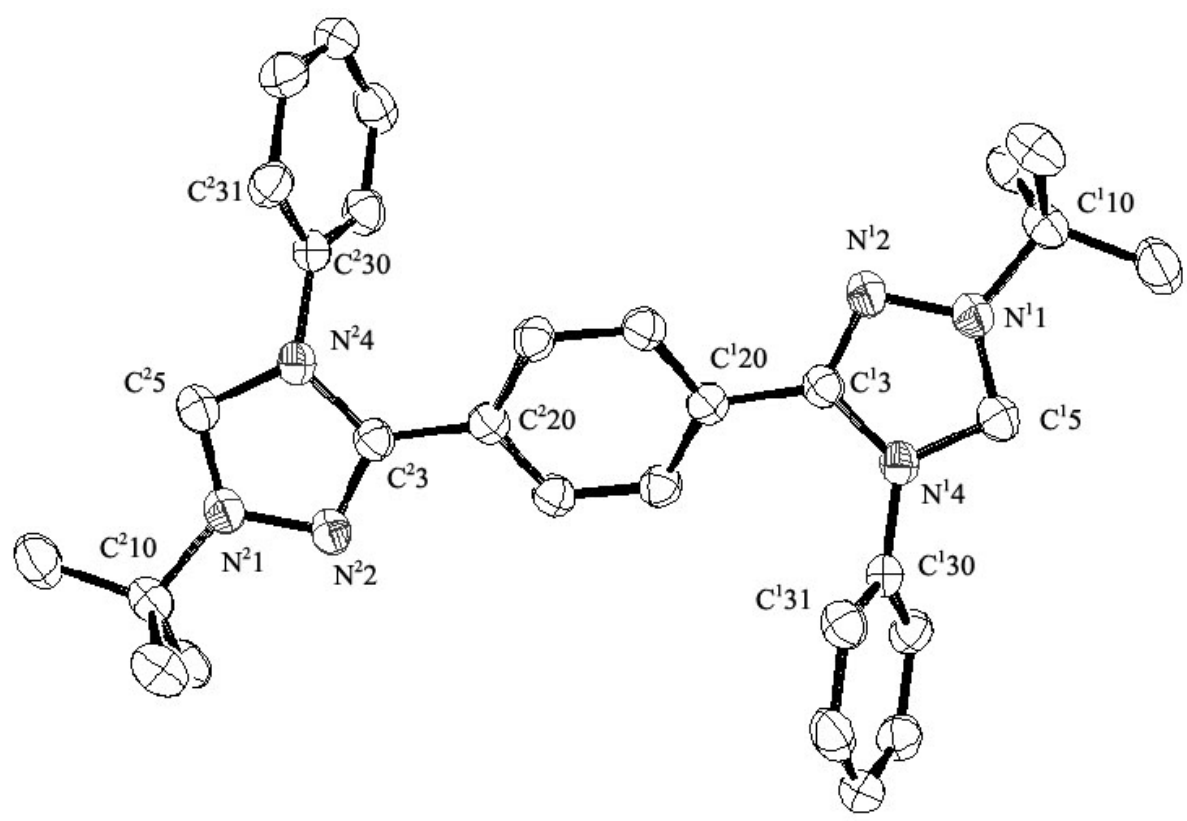

Figure 1. View of carbene $\mathbf{5 d}$ showing thermal ellipsoids at 50\% probability.

Table 1. Selected bond lengths $(\AA)$, internal angles $(\theta$, deg) and torsion angles $(\varphi, \operatorname{deg})$ as determined by single-crystal X-ray diffraction of biscarbene $\mathbf{5 d}$ and model 1-tert-butyl-3phenyl-4-(4-bromophenyl)-1,2,4-triazol-5-ylidene A

\begin{tabular}{|c|c|c|}
\hline Bond or angle & 5d & A \\
\hline $\mathrm{C} 5-\mathrm{N} 1$ & $1.343(3)$ & $1.335(3)$ \\
\hline $\mathrm{C} 5-\mathrm{N} 4$ & $1.385(3)$ & $1.388(3)$ \\
\hline $\mathrm{N} 1-\mathrm{N} 2$ & $1.392(2)$ & $1.393(2)$ \\
\hline $\mathrm{C} 3=\mathrm{N} 2$ & $1.304(2)$ & $1.306(3)$ \\
\hline $\mathrm{C} 3-\mathrm{N} 4$ & $1.383(3)$ & $1.379(3)$ \\
\hline $\mathrm{N} 1-\mathrm{C} 10$ & $1.482(2)$ & $1.489(3)$ \\
\hline $\mathrm{C} 3-\mathrm{C} 20$ & $1.473(3)$ & $1.479(3)$ \\
\hline $\mathrm{N} 4-\mathrm{C} 30$ & $1.441(3)$ & $1.433(3)$ \\
\hline$\theta(\mathrm{N} 1-\mathrm{C} 5-\mathrm{N} 4)$ & $100.4(2)$ & $100.7(2)$ \\
\hline$\varphi(\mathrm{N} 2-\mathrm{C} 3-\mathrm{C} 20-\mathrm{C} 21)$ & $-29.7(3)$ & $-29.9(2)$ \\
\hline$\varphi(\mathrm{C} 3-\mathrm{N} 4-\mathrm{C} 30-\mathrm{C} 31)$ & $-58.9(3)$ & $-51.1(2)$ \\
\hline
\end{tabular}


Thus, similar to the mononuclear compound $\mathbf{A}$, in bistriazolylidene $\mathbf{5 d}$ the cyclic bonds are significantly delocalized and the bond order of the $\mathrm{C}(5)-\mathrm{N}(1)$ bond is indicative of an appreciable contribution of the ylidic resonance form of a triazolylidene ring. It should be noted that despite the almost identical twist angles of the phenylene group in mono- and biscarbenes with N-tert-butyl substituents, the spectral properties and chemical reactivities of these species differ appreciably. For example, the biscarbenes are distinctly less reactive toward electrophiles and more stable upon storage.

In order to evaluate the reactivity patterns of bistriazolylidenes, their reactions with sulfur (a known trap for carbenes), diphenyldiazomethane, and copper (I) salts were investigated. Bisthione $\mathbf{6}$ is formed easily and in $93 \%$ yield upon treatment of carbene $\mathbf{5 d}$ with sulfur in toluene solution at $25{ }^{\circ} \mathrm{C}$. The reaction of biscarbene $\mathbf{5 d}$ with diphenyldiazomethane results in exclusive formation of the yellow colored azine 7. Nucleophilic substitution of nitrogen in diazocompounds to form the corresponding bisdiphenylmethylenbisazolines was not observed.

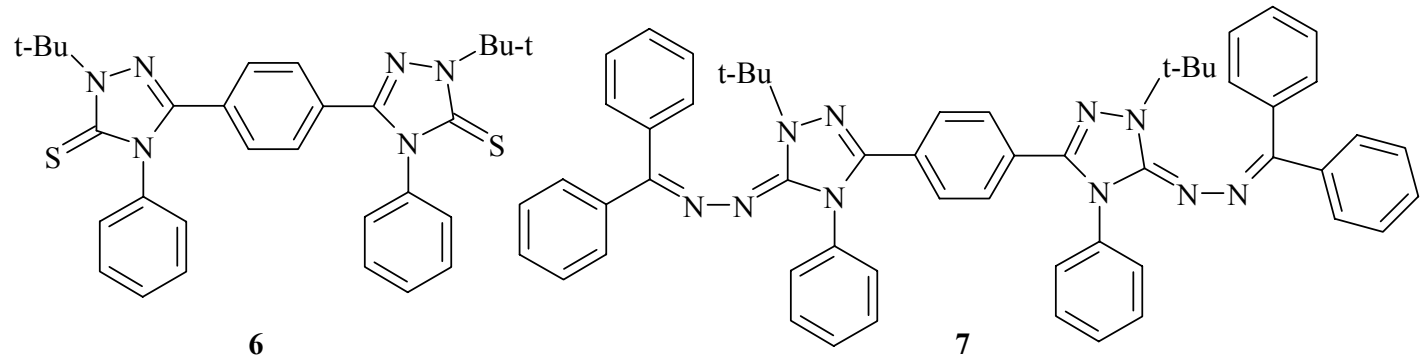

The interaction of biscarbene $\mathbf{5 b}$ with $\mathrm{CuCl}$ affords the corresponding biscarbene complex $\mathbf{8}$ (Scheme 3). The preparation of copper complexes of type $\mathbf{8}$ in acetonitrile solution is accompanied by the formation of unidentified green colored products, the formation of which is significantly decreased if the reaction is carried out in a 1:1 mixture of acetonitrile and THF. The carbene complex with $\mathrm{CuI}$ of type $\mathbf{8}$ was also isolated initially in almost quantitative yield. However, when attempts were made to recrystallize these compounds from polar, high boiling solvents (DMF, DMSO), they underwent complete transformation to dark-colored products. In the case of the copper chloride complex 8 the impurities can be completely separated by filtration through silica gel using a 10:1 mixture of chloroform and methanol.

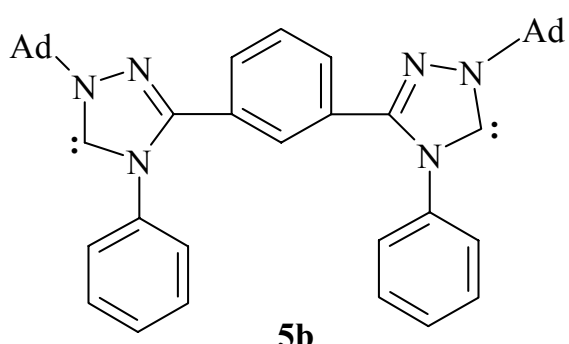

$\mathbf{5 b}$

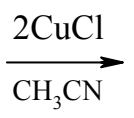

\section{Scheme 3}


The compositions and structures of compounds 6-8 were established by elemental analysis, and ${ }^{1} \mathrm{H}$ and ${ }^{13} \mathrm{C}$ NMR spectroscopy. The purities of the new compounds were estimated by ${ }^{1} \mathrm{H}$ NMR spectroscopy and TLC.

The ${ }^{1} \mathrm{H}$ NMR spectrum of thione $\mathbf{6}$ features the anticipated resonances for the aromatic and adamantyl protons and are downfield with respect to those for biscarbene $\mathbf{5 d}$. The appropriate resonances for the aromatic and methyl protons of azine 7 were evident in the ${ }^{1} \mathrm{H}$ NMR spectrum. The ${ }^{1} \mathrm{H}$ NMR spectrum of complex $\mathbf{8}$ shows a weakened influence of the carbene carbon on the shielding of the adamantyl $\mathrm{CH}_{2}$ group connected to a triazole ring ( $\left.\Delta \delta 0.23 \mathrm{ppm}\right)$. The chemical shift is close to those of triazolium salts $(\delta 2.24-2.29 \mathrm{ppm})$. In the ${ }^{13} \mathrm{C} \mathrm{NMR}$ spectrum of copper complex $\mathbf{8}$ the carbene resonance is upfield of that for carbene $\mathbf{5 b}(\Delta \delta 31$ ppm, up to $176 \mathrm{ppm}$ ) and falls within the typical range for metal carbene complexes.

Crystals of complex 8 suitable for single-crystal X-ray diffraction experiments were grown from acetonitrile. This study revealed a trans-oriented molecular structure for $\mathbf{8}$ (Figure 2, Table 2). The triazole ring retains its polarity. For example, the C-N-N-C angle is $0.7^{\circ}$ while that for the second nucleus and previously isolated mononuclear triazole carbenes is $-0.1^{\circ}{ }^{17} \mathrm{The} \mathrm{Cu}-\mathrm{Cl}$ bond distance in complex $8(2.10 \AA)$ is shorter than that in crystalline copper chloride $(2.34 \AA),{ }^{18}$ thus evidencing more covalent character for this bond than in the case of complex $\mathbf{8}$. The $\mathrm{Cu}-\mathrm{Cl}$ bond distance in $\mathbf{8}$ is very similar to that in the tetrahydropyrimidin-2-ylidene complex $9 .{ }^{19}$

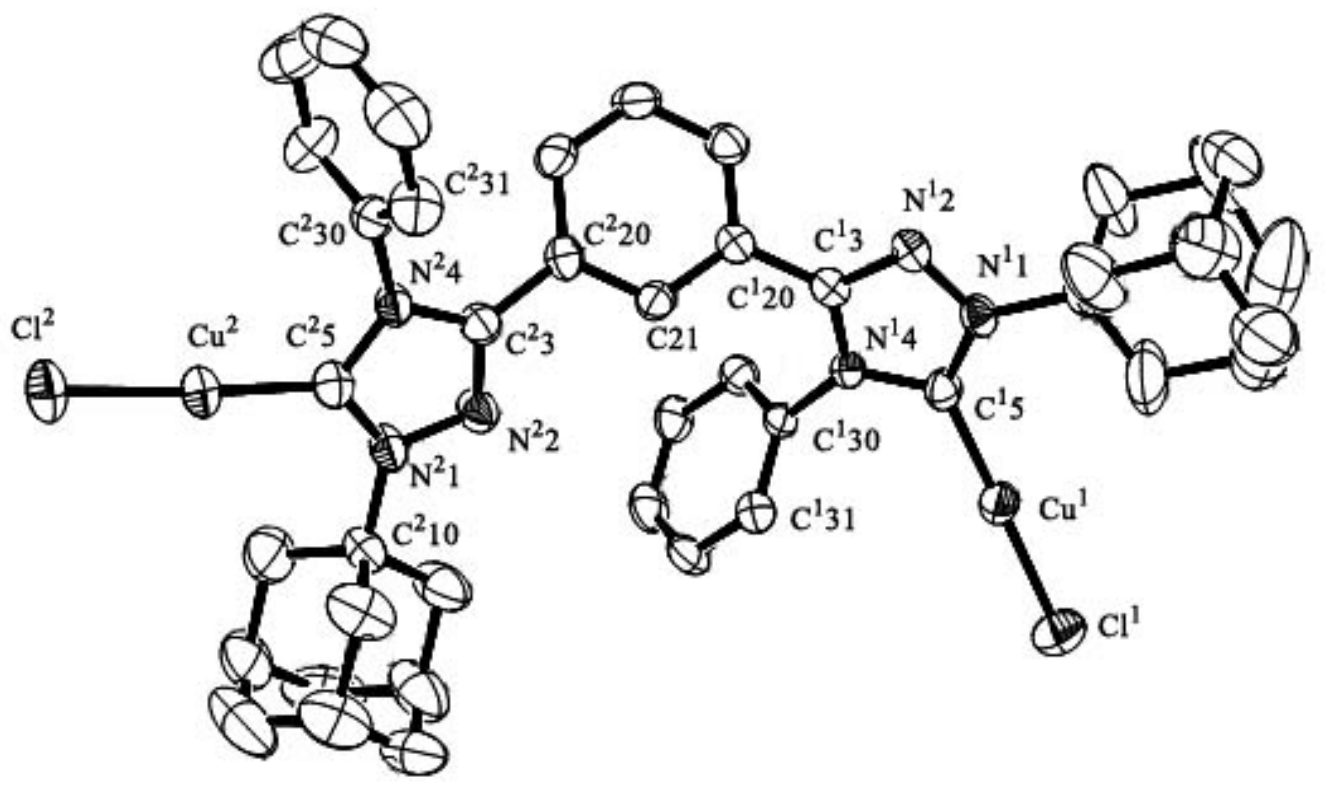

Figure 2. View of carbene complex 8 showing thermal ellipsoids at 50\% probability.

The $\mathrm{Cu}-\mathrm{C}(5)$ bond in complex $\mathbf{8}$ is shorter (1.87-1.88 $\AA$ ) than those in the corresponding tetrahydropyrimidin-2-ylidene $(1.91 \AA)$ and N-oxazolinylimidazol-2-ylidene 10 (1.90 $\AA$ ) complexes. $^{20}$ This observation can be attributed to the greater donor strength of the triazole 
carbene. However, such a suggestion is not in accord with the accepted view of the donor ability of 1,2,4-triazol-5-ylidenes in comparison with those of imidazol-2-ylidenes and especially acyclic carbenes and tetrahydropyrimidines. ${ }^{19}$ The explanation for this apparent contradiction might be the increased bond order of the $\mathrm{Cu}-\mathrm{C}(5)$ bond in complex $\mathbf{8}$ due to back donation of the metal to the heterocyclic nucleus.<smiles>[R]N1CCCN([R])C1CCl</smiles>

9<smiles>[R]C1([R])COC2=C(Cl)N(C)C([Al])N2C=CN1[AlH2]</smiles>

10

Table 2. Selected bond lengths $(\AA)$, internal angles $(\theta, \mathrm{deg})$ and torsion angles $(\varphi, \mathrm{deg})$ for biscarbene complex $\mathbf{8}$ as determined by single-crystal X-ray diffraction

\begin{tabular}{|c|c|c|}
\hline Bond or angle & $\mathbf{8}(1)$ & $\mathbf{8}(2)$ \\
\hline $\mathrm{r}(\mathrm{C} 5-\mathrm{N} 1)$ & $1.337(4)$ & $1.355(5)$ \\
\hline $\mathrm{r}(\mathrm{C} 5-\mathrm{N} 4)$ & $1.373(5)$ & $1.361(5)$ \\
\hline $\mathrm{r}(\mathrm{N} 1-\mathrm{N} 2)$ & $1.372(4)$ & $1.385(4)$ \\
\hline $\mathrm{r}(\mathrm{C} 3=\mathrm{N} 2)$ & $1.311(4)$ & $1.308(5)$ \\
\hline $\mathrm{r}(\mathrm{C} 3-\mathrm{N} 4)$ & $1.365(4)$ & $1.377(5)$ \\
\hline $\mathrm{r}(\mathrm{N} 1-\mathrm{C} 10)$ & $1.492(5)$ & $1.485(5)$ \\
\hline $\mathrm{r}(\mathrm{C} 3-\mathrm{C} 20)$ & $1.473(5)$ & $1.484(5)$ \\
\hline $\mathrm{r}(\mathrm{N} 4-\mathrm{C} 30)$ & $1.443(4)$ & $1.444(5)$ \\
\hline $\mathrm{r}(\mathrm{Cu}-\mathrm{Cl})$ & $2.1014(12)$ & $2.0985(13)$ \\
\hline $\mathrm{r}(\mathrm{Cu}-\mathrm{C} 5)$ & $1.876(4)$ & $1.880(4)$ \\
\hline$\theta(\mathrm{N} 1-\mathrm{C} 5-\mathrm{N} 4)$ & $102.3(3)$ & $103.2(3)$ \\
\hline$\varphi(\mathrm{C} 5-\mathrm{N} 1-\mathrm{N} 2-\mathrm{C} 3)$ & $-0.1(4)$ & $0.7(4)$ \\
\hline$\varphi(\mathrm{N} 2-\mathrm{C} 3-\mathrm{C} 20-\mathrm{C} 21)$ & $140.2(3)$ & $-30.6(5)$ \\
\hline
\end{tabular}

\section{Experimental Section}

General Procedures. All experiments with biscarbenes 5a-d were carried out under a nitrogen or argon atmosphere. All solvents were dried by standard methods prior to use. ${ }^{1} \mathrm{H}$ and ${ }^{13} \mathrm{C}$ NMR chemical shifts are reported relative to tetramethylsilane (TMS, $\delta=0.00$ ) as internal standard. IR spectra were measured as Nujol mulls and thin-layer chromatography was performed on silica gel with chloroform or a 10:1 mixture of chloroform and methanol as eluent, followed by 
development with iodine. Elemental analyses were carried out at the Analytical Laboratory of the Litvinenko Institute of Physical Organic and Coal Chemistry. Triazoles 2a-c were obtained by ring transformations of the respective bisoxadiazoles 1a-c with anilines in $o$-dichlorobenzene solution in the presence of trifluoroacetic acid at $180^{\circ} \mathrm{C}$ according to the literature method. ${ }^{7}$

1,4-Bis(1-adamantyl-4-phenyl-1,2,4-triazolium-3-yl)benzene salts (3a-c). General procedure A solution of bistriazole $2 \mathbf{2 a - c}(10 \mathrm{mmol})$ and 1-bromoadamantane $(6.45 \mathrm{~g}, 30 \mathrm{mmol})$ in acetic acid $(10 \mathrm{~mL})$ was refluxed for $9-15 \mathrm{~h}$. The reaction mixture was diluted with water (150-250 $\mathrm{mL}$ ), filtered with activated charcoal in a hot state, then evaporated to the onset of crystallization. Following this, one of the following methods was used: (a) the reaction mixture was cooled and the resulting precipitate of bromide $3 \mathbf{a}$ was filtered off; (b) a solution of sodium perchlorate (4.3 $\mathrm{g}$, $35 \mathrm{mmol}$ ) was added and the precipitates of perchlorates 3b,c were filtered off. Yields 73-77 \%.

Bromide 3a. Yield $73 \%, \mathrm{mp}>300{ }^{\circ} \mathrm{C}$ (water). $\mathrm{R}_{\mathrm{f}}$ 0.30. ${ }^{1} \mathrm{H}$ NMR (DMSO-d $\mathrm{d}_{6}, 200 \mathrm{MHz}$ ): 1.78 (s, 12H, $\left.\mathrm{CH}_{2} \mathrm{C}\right), 2.29$ (s, 18H, $\left.\mathrm{CH}_{2} \mathrm{C}, \mathrm{CHC}\right), 7.59$ (m, $\left.14 \mathrm{H}, \mathrm{Ar}\right), 10.65$ (s, 2H, CHN). Anal. Calcd. for $\mathrm{C}_{42} \mathrm{H}_{46} \mathrm{Br}_{2} \mathrm{~N}_{6}$ : C, 63.5; H, 5.8; Br, 20.1; N, 10.6. Found: C, 63.2; H, 5.9; Br, 19.9; N, 10.5 .

Perchlorate 3b. Yield $77 \%, \mathrm{mp}>233-235{ }^{\circ} \mathrm{C}$ (water-acetic acid, 1:1). $\mathrm{R}_{\mathrm{f}} 0.64 .{ }^{1} \mathrm{H}$ NMR (DMSO-d 6 , $200 \mathrm{MHz}): 1.81\left(\mathrm{~m}, 12 \mathrm{H}, \mathrm{CH}_{2} \mathrm{C}\right), 2.29$ (m, 18H, $\left.\mathrm{CH}_{2} \mathrm{C}, \mathrm{CHC}\right), 7.52-7.66$ (m, 14H, Ar), 10.65 (s, 2H, CHN). Anal. Calcd. for $\mathrm{C}_{42} \mathrm{H}_{46} \mathrm{Cl}_{2} \mathrm{~N}_{6} \mathrm{O}_{8}: \mathrm{C}, 60.5 ; \mathrm{H}, 5.6 ; \mathrm{Cl}, 8.5 ; \mathrm{N}, 10.1$. Found: C, 60.3; H, 5.3; Cl, 8.5; N, 9.9.

Perchlorate 3c. Yield $77 \%$, mp 290-293 ${ }^{\circ} \mathrm{C}$ (acetonitrile). $\mathrm{R}_{\mathrm{f}}$ 0.60. ${ }^{1} \mathrm{H}$ NMR (DMSO- $\mathrm{d}_{6}, 200$ MHz): $1.81\left(\mathrm{~m}, 12 \mathrm{H}, \mathrm{CH}_{2} \mathrm{C}\right), 2.29\left(\mathrm{~m}, 18 \mathrm{H}, \mathrm{CH}_{2} \mathrm{C}, \mathrm{CHC}\right), 7.52-7.66(\mathrm{~m}, 14 \mathrm{H}, \mathrm{Ar}), 10.65$ (s, 2H, $\mathrm{CHN}$ ). Anal. Calcd. for $\mathrm{C}_{40} \mathrm{H}_{48} \mathrm{Br}_{2} \mathrm{~N}_{6} \mathrm{Cl}_{2} \mathrm{O}_{8}: \mathrm{C}, 59.0 ; \mathrm{H}, 6.2 ; \mathrm{Cl}, 8.7 ; \mathrm{N}, 10.3$. Found: $\mathrm{C}, 59.2 ; \mathrm{H}$, $6.0 ; \mathrm{Cl}, 8.8 ; \mathrm{N}, 10.5$.

1,4-Bis(1-tert-butyl-4-phenyl-1,2,4-triazolium-3-yl)benzene diperchlorate (3d). A mixture of bistriazole 2a (3.2 g, $8.8 \mathrm{mmol})$, tert-butyl chloride (4.88 g, $52.7 \mathrm{mmol})$, and sodium iodide (7.9 $\mathrm{g}, 52.7 \mathrm{mmol})$ in acetic acid $(25 \mathrm{~mL})$ was refluxed for $3 \mathrm{~h}$. The reaction mixture was poured into water, triturated with activated charcoal, heated to boiling and filtered hot. Then sodium perchlorate $(2.45 \mathrm{~g}, 20 \mathrm{mmol})$ was added, and the resulting precipitate was filtered off and dried. Yield $5.1 \mathrm{~g}(86 \%)$. mp 262-263 ${ }^{\circ} \mathrm{C}$ (water-DMF, 1:1). $\mathrm{R}_{\mathrm{f}} 0 .{ }^{1} \mathrm{H}$ NMR (DMSO-d $6,200 \mathrm{MHz}$ ): $1.74\left(\mathrm{~s}, 18 \mathrm{H}, \mathrm{CH}_{3}\right), 7.55,7.62(\mathrm{~m}, 14 \mathrm{H}, \mathrm{Ar}), 10.65(\mathrm{~s}, 2 \mathrm{H}, \mathrm{CHN})$. Anal. Calcd. for $\mathrm{C}_{30} \mathrm{H}_{34} \mathrm{~N}_{6} \mathrm{Cl}_{2} \mathrm{O}_{8}$ : C, 53.2; H, 5.0; Cl, 10.5; N, 12.4. Found: C, 53.1; H, 4.9; Cl, 10.7; N, 12.2 .

1,4-Bis(1-benzyl-4-phenyl-1,2,4-triazolium-3-yl)benzene diperchlorate (3e). A mixture of triazole $2 \mathrm{a}(2 \mathrm{~g}, 5.4 \mathrm{mmol})$, benzyl chloride $(2.05 \mathrm{~g}, 16.2 \mathrm{mmol})$ in acetic acid $(1.5 \mathrm{~mL})$ was refluxed for $8 \mathrm{~h}$. The reaction mixture was dissolved in water $(50 \mathrm{~mL})$ and sodium perchlorate $(1.22 \mathrm{~g}, 10 \mathrm{mmol})$ was then added. The resulting precipitate was filtered off and dried. Yield $3.06 \mathrm{~g}\left(76 \%\right.$ ). mp 295-296 ${ }^{\circ} \mathrm{C}$ (water-DMF, 1:1). $\mathrm{R}_{\mathrm{f}}$ 0.30. ${ }^{1} \mathrm{H}$ NMR (DMSO-d 6 , $200 \mathrm{MHz}$ ): 5.76 $\left(\mathrm{s}, 4 \mathrm{H}, \mathrm{CH}_{2} \mathrm{~N}\right), 7.48,7.50,7.61(\mathrm{~m}, 24 \mathrm{H}, \mathrm{Ar}), 10.77(\mathrm{~s}, 2 \mathrm{H}, \mathrm{CHN})$. Anal. Calcd. for $\mathrm{C}_{36} \mathrm{H}_{30} \mathrm{Cl}_{2} \mathrm{~N}_{6} \mathrm{O}_{8}$ : C, 57.9; H, 4.0; Cl, 9.5; N, 11.3. Found: C, 58.1; H, 4.1; Cl, 9.4; N, 11.3. 
1,4-Bis(1-adamantyl-4-phenyl-1,2,4-triazol-5-yliden-3-yl)benzene (5a). (a) A mixture of the anhydrous salt 3a $(1.0 \mathrm{~g}, 1.25 \mathrm{mmol})$ and potassium tert-butoxide $(0.28 \mathrm{~g}(2.50 \mathrm{mmol})$ in anhydrous methanol $(10 \mathrm{~mL})$ was stirred under an inert atmosphere for $15 \mathrm{~min}$, then toluene (10 $\mathrm{mL}$ ) was then added and the resulting mixture was stirred for $15 \mathrm{~min}$. The precipitate that formed was filtered off and the filtrate was evaporated in vacuo. The resulting product was dried for 40 $\min$ at $70-80{ }^{\circ} \mathrm{C}(0.79 \mathrm{~g})$ and purified by extraction with anhydrous toluene $(65 \mathrm{~mL})$. After removing the solvent $0.67 \mathrm{~g}(85 \%)$ of biscarbene 5a was obtained and recrystallized from toluene solution. $\mathrm{mp} 208-210{ }^{\circ} \mathrm{C}$ (toluene). ${ }^{1} \mathrm{H} \mathrm{NMR}\left(\mathrm{C}_{6} \mathrm{D}_{6}-\mathrm{Py}-\mathrm{D}_{5}, 1: 1,200 \mathrm{MHz}\right): 1.70$ (m, 12H, Ad), 2.15 (m, 6H, Ad), 2.62 (m, 12H, Ad), $7.12-7.45$ (m, Ar.). ${ }^{13} \mathrm{C}$ NMR ( $\mathrm{C}_{6} \mathrm{D}_{6}-\mathrm{Py}-\mathrm{d}_{5}, 1: 1,50.3$ MHz): 30.8, 37.2, 44.5, 60.8 (Ad), 127.5, 129.2, 130.1, 130.8 (Ar), 140.3 (ipso-CN), 206.6 (C5). IR spectrum (nujol mull), $\mathrm{sm}^{-1}: 1600 \mathrm{w}, 1500 \mathrm{~m}(\mathrm{C}=\mathrm{C}$ arom.), $1305 \mathrm{~m}, 1200 \mathrm{w}, 1150 \mathrm{~m}, 980 \mathrm{w}$, 830 w, 715 m, 660 w, 630 w, 600 w, 575 m, 500 s, 480 s, 425 s. Anal. Calcd. for $\mathrm{C}_{42} \mathrm{H}_{44} \mathrm{~N}_{6}$ : C, 79.7; H, 7.0; N, 13.3. Found: C, 79.7; H, 7.1; N, 13.5.

(b) A mixture of anhydrous salt $3 \mathbf{a}(0.3 \mathrm{~g}, 0.36 \mathrm{mmol})$ and potassium tert-butoxide $(0.08 \mathrm{~g}, 0.72$ mmol) was stirred in anhydrous toluene $(5 \mathrm{~mL})$ under a nitrogen atmosphere for $1 \mathrm{~h}$. The inorganic salt was filtered off and the filtrate was evaporated in vacuo. The resulting product was triturated with petroleum ether $(2 \mathrm{~mL})$, filtered off, dried, and purified $(0.16 \mathrm{~g})$ according to Procedure (a). This method resulted in the isolation of $0.13 \mathrm{~g}$ (57\% yield) of 5a.

(c) A $15 \%$ solution of potassium hexamethyldisilazanide $(1.67 \mathrm{~g}, 1.26 \mathrm{mmol})$ was added to a dispersion of salt $3 \mathbf{a}(0.5 \mathrm{~g}, 0.63 \mathrm{mmol})$ in $10 \mathrm{~mL}$ of a $50 / 50$ mixture of anhydrous toluene and tetrahydrofuran and stirred under a nitrogen atmosphere for $1 \mathrm{~h}$. The inorganic salt was filtered off and the filtrate was evaporated in vacuo. The resulting product was stirred with petroleum ether $(2 \mathrm{~mL})$, filtered off and dried. The product $(0.26 \mathrm{~g}, 65 \%)$ is suitable for further synthetic use without additional purification.

1,3-Bis(1-adamantyl-4-phenyl-1,2,4-triazol-5-yliden-3-yl)benzene (5b). (a) A mixture of anhydrous salt $\mathbf{3 b}(1 \mathrm{~g}, 1.2 \mathrm{mmol})$ and potassium tert-butoxide $(0.27 \mathrm{~g}, 2.4 \mathrm{mmol})$ in toluene solution $(12 \mathrm{~mL})$ was stirred under a nitrogen atmosphere for $1 \mathrm{~h}$. The inorganic precipitate was filtered off and the filtrate was evaporated in vacuo. The resulting product was triturated with petroleum ether $(2 \times 3 \mathrm{~mL})$, filtered off and dried. Yield of biscarbene $\mathbf{5 b} 0.49 \mathrm{~g}(64 \%)$. mp 178$180{ }^{\circ} \mathrm{C}$ (acetonitrile). ${ }^{1} \mathrm{H}$ NMR $\left(\mathrm{C}_{6} \mathrm{D}_{6}, 200 \mathrm{MHz}\right): 1.69$ (m, 12H, Ad), 2.14 (m, 6H, Ad), 2.61 (m, 12H, Ad), 6.97 (m, 5H), $7.25(\mathrm{~m}, 8 \mathrm{H}), 8.20(\mathrm{~s}, 1 \mathrm{H})(\mathrm{Ar}) .{ }^{13} \mathrm{C} \mathrm{NMR}\left(\mathrm{C}_{6} \mathrm{D}_{6}, 50.3 \mathrm{MHz}\right): 30.0$, 37.5, 43.8, 59.8 (Ad), 126.6, 127.6, 128.2, 129.0, 129.2, 129.7 (Ar), 123.3 (ipso-CC), 130.0 (ipso-CN), 150.2 (C3), 207.1 (C5). Anal. Calcd for $\mathrm{C}_{42} \mathrm{H}_{44} \mathrm{~N}_{6}$ : C, 79.7; H, 7.0; N, 13.5. Found, $\%$ : C, 80.1; H, 7.2; N, 13.3 .

(b) A solution of the anhydrous salt $3 \mathbf{b}(0.5 \mathrm{~g}, 0.6 \mathrm{mmol})$ in acetonitrile $(8 \mathrm{~mL})$ was cooled to $45^{\circ} \mathrm{C}$, then sodium hydride $(0.03 \mathrm{~g}(1.2 \mathrm{mmol})$ was added and the reaction mixture was heated to room temperature. After completion of the hydrogen evolution the reaction mixture was evaporated in vacuo and the resulting residue was extracted with toluene $(5 \mathrm{~mL})$. The toluene was evaporated under reduced pressure and the product was stirred with petroleum ether $(2 \mathrm{~mL})$ and dried. Yield $0.26 \mathrm{~g}(68 \%)$ of biscarbene $\mathbf{5 b}$. 
1,4-Bis(1-adamantyl-4-phenyl-1,2,4-triazol-5-yliden-3-yl)butane (5c). A mixture of the anhydrous salt $3 \mathbf{c}(0.5 \mathrm{~g}, 0.51 \mathrm{mmol})$ and potassium tert-butoxide $(0.12 \mathrm{~g}, 1 \mathrm{mmol})$ in anhydrous toluene $(5 \mathrm{~mL})$ was stirred under a nitrogen atmosphere for $1 \mathrm{~h}$. The inorganic precipitate was filtered off and the filtrate was evaporated in vacuo. The resulting product was triturated with 2 $\mathrm{mL}$ of a 1:3 mixture of toluene and petroleum ether, then filtered off and dried. Yield $0.3 \mathrm{~g}$ (77 \%) of biscarbene 5c. mp $135-138{ }^{\circ} \mathrm{C}$ (benzene-petroleum ether, 1:3). ${ }^{1} \mathrm{H} \mathrm{NMR}\left(\mathrm{C}_{6} \mathrm{D}_{6}, 200 \mathrm{MHz}\right)$ : 1.62 (m, 12H, Ad; 4H, $\left.\mathrm{CH}_{2} \mathrm{C}\right), 2.09$ (m, 6H, CHC, Ad), $2.30\left(\mathrm{~m}, 4 \mathrm{H}, \mathrm{CH}_{2} \mathrm{~N}\right), 2.57$ (m, 12H, Ad), 6.95 (m, 4H, Ar), 7.15 (m, 4H, Ar). ${ }^{13} \mathrm{C}$ NMR $\left(\mathrm{C}_{6} \mathrm{D}_{6}, 50.3 \mathrm{MHz}\right): 25.2,26.9\left(\mathrm{CH}_{2}\right.$ aliph.), 30.4, 36.7, 44.3, 59.5 (Ad), 129.2, 132.6 (Ar), 121.9 (ipso-CC), 139.1 (ipso-CN), 151.0 (C3), 208.1 (C5). Anal. Calcd for $\mathrm{C}_{40} \mathrm{H}_{46} \mathrm{Br}_{2} \mathrm{~N}_{6}$ : C, 63.6; H, 5.6; Br 20.2; N, 10.6. Found, \%: C, 63.5; H, 5.4; Br 20.4; N, 10.6.

1,4-Bis(1-tert-butyl-4-phenyl-1,2,4-triazol-5-yliden-3-yl)benzene (5d). A solution of the anhydrous salt 3d $(0.6 \mathrm{~g}, 0.89 \mathrm{mmol})$ in acetonitrile $(15 \mathrm{~mL})$ was cooled to $-45^{\circ} \mathrm{C}$, following which sodium hydride $(0.043 \mathrm{~g}, 1.77 \mathrm{mmol})$ was added and the stirred reaction mixture was heated to room temperature. After completion of the hydrogen evolution the precipitate was filtered off, washed with acetonitrile $(2 \mathrm{~mL})$ and dried for $30 \mathrm{~min}$ at $150{ }^{\circ} \mathrm{C}$ in vacuo. Yield 0.36 $\mathrm{g}(86 \%)$. mp 196-197 ${ }^{\circ} \mathrm{C}$ (toluene-THF, 1:1). ${ }^{1} \mathrm{H}$ NMR $\left.\left(\mathrm{C}_{6} \mathrm{D}_{6}-\mathrm{Py}-\mathrm{D}_{6}, 1: 1\right), 200 \mathrm{MHz}\right): 1.80$ (s, 18H, $\left.\mathrm{CH}_{3}\right), 7.12-7.36$ (m, 10H, Ar). ${ }^{13} \mathrm{C} \mathrm{NMR}\left(\mathrm{C}_{6} \mathrm{D}_{6}-\mathrm{Py}-\mathrm{D}_{6}, 1: 1,50.3 \mathrm{MHz}\right): 30.8\left(\mathrm{CH}_{3} \mathrm{C}\right), 60.5$ $\left(\mathrm{CH}_{3} \mathrm{C}\right.$ ), 126.1, 127.1, 128.0, 129.4, 129.7 (Ar), 139.5 (ipso-CN), 150.9 (C3), 202.9 (C5). Anal. Calcd for $\mathrm{C}_{30} \mathrm{H}_{32} \mathrm{~N}_{6}$ : C, 75.6; H, 6.8; N, 17.6. Found, \%: C, 75.3; H, 6.8; N, 17.6.

1,4-Bis(1-tert-butyl-4-phenyl-1,2,4-triazol-5-thion-3-yl)benzene (6). A solution of sulfur (0.1 $\mathrm{g}, 3.1 \mathrm{mmol})$ in anhydrous toluene $(5 \mathrm{~mL})$ was added to a solution of carbene $\mathbf{5 d}(0.38 \mathrm{~g}, 0.80$ $\mathrm{mmol})$ in toluene $(5 \mathrm{~mL})$ under a nitrogen atmosphere and the resulting solution was stirred at room temperature for several minutes. The resulting voluminous precipitate was filtered off and dried. Yield $0.4 \mathrm{~g}(93 \%)$. The product was recrystallized from dimethylformamide $(15 \mathrm{~mL})$ to afford $0.28 \mathrm{~g}(70 \%)$ of pure thione 6. $\mathrm{mp}>300{ }^{\circ} \mathrm{C}$ (dimethylformamide). $\mathrm{R}_{\mathrm{f}} 0.93$. ${ }^{1} \mathrm{H}$ NMR $\left(\mathrm{CDCl}_{3}, 200 \mathrm{MHz}\right): 1.81(\mathrm{~s}, 9 \mathrm{H}, t-\mathrm{Bu}), 7.22(\mathrm{~m}, 4 \mathrm{H}), 7.28(\mathrm{~m}, 4 \mathrm{H}), 7.45(\mathrm{~m}, 6 \mathrm{H})$ (Ar). Anal. Calcd for $\mathrm{C}_{30} \mathrm{H}_{32} \mathrm{~N}_{6} \mathrm{~S}_{2}: \mathrm{C}, 66.6 ; \mathrm{H}, 6.0 ; \mathrm{S} 11.9 ; \mathrm{N}, 15.5$. Found, \%: C, 66.3; H, 6.2; S 12.0; N, 15.5.

\section{1,4-Bis(1-tert-butyl-4-phenyl-1,2,4-triazol-5-on-3-yl)benzenebis(diphenylmethylene)azine}

(7). A mixture of biscarbene $5 \mathbf{d}(0.2 \mathrm{~g}, 0.42 \mathrm{mmol})$ and diphenyldiazomethane $(0.16 \mathrm{~g}, 0.84$ $\mathrm{mmol})$ was stirred in tetrahydrofuran $(4 \mathrm{~mL})$ for $2 \mathrm{~h}$. The resulting precipitate formed was filtered off and dried. Yield $0.17 \mathrm{~g}(47 \%) . \mathrm{mp}>300{ }^{\circ} \mathrm{C}(\mathrm{DMF}) . \mathrm{R}_{\mathrm{f}} 0.95 .{ }^{1} \mathrm{H} \mathrm{NMR}\left(\mathrm{CF}_{3} \mathrm{COOH}\right.$, $200 \mathrm{MHz}$ ): 1.75 (s, $\mathrm{CH}_{3} \mathrm{C}$ ), 7.05-7.76 (m, 34H, Ar). Anal. Calcd for $\mathrm{C}_{56} \mathrm{H}_{52} \mathrm{~N}_{10}$ : C, 77.6; H, 6.3; N, 16.2. Found, \%: C, 77.8; H, 6.1; N, 16.2.

Complex of 1,3-bis(1-adamantyl-4-phenyl-1,2,4-triazol-5-yliden-3-yl)benzene with CuCl (8). A suspension of biscarbene $5 \mathbf{b}(0.28 \mathrm{~g}, 0.44 \mathrm{mmol})$ and copper (I) chloride (0.088 $\mathrm{g}, 0.88$ mmol) in a 1:1 mixture of tetrahydrofuran and acetonitrile was stirred for $2 \mathrm{~h}$. The solution was evaporated in vacuo and filtered through a thin layer of silica gel in chloroform. The resulting solution was evaporated to afford complex 8 in $0.33 \mathrm{~g}(90 \%)$ yield, mp $268-270{ }^{\circ} \mathrm{C}$ 
(acetonitrile). $\mathrm{R}_{\mathrm{f}}$ 0.97. ${ }^{1} \mathrm{H}$ NMR (DMSO-d $\mathrm{d}_{6}, 200 \mathrm{MHz}$ ): 1.75 (s, $\mathrm{CH}_{3}$ ), 7.05-7.76 (m, 34H, Ar). ${ }^{13}$ C NMR (DMSO-d 6 , $50.3 \mathrm{MHz}$ ): 29.0, 35.2, 43.0, 60.8 (Ad), 127.0, 128.9, 129.1, 129.7, 129.8, 130.5 (Ar), 125.2 (ipso-CC), 136.7 (ipso-CN), 149.8 (C3), 176.5 (C5). Anal. Calcd for $\mathrm{C}_{42} \mathrm{H}_{44} \mathrm{Cl}_{2} \mathrm{~N}_{6} \mathrm{Cu}_{2}: \mathrm{C}, 60.7 ; \mathrm{H}, 5.3 ; \mathrm{Cl} 8.5 ; \mathrm{N}, 10.1$. Found, \%: C, 60.3; H, 5.0; $\mathrm{Cl}$ 8.7; N, 9.9.

\section{X-ray Crystallography}

Crystals of $\mathbf{5 d}$ and $\mathbf{8}$ were removed from sealed vials, placed on glass slides, covered with degassed hydrocarbon oil, and mounted on thin nylon loops. The X-ray diffraction data were collected at 153(2) K on a Nonius Kappa CCD area detector diffractometer equipped with an Oxford Cryostream low-temperature device and a graphite-monochromated Mo-Ka radiation source $(\lambda=0.71073 \AA)$. Corrections were applied for Lorentz and polarization effects. Both structures were solved by direct methods and refined by full-matrix least-squares cycles on $\mathrm{F}^{221}$. All non-hydrogen atoms were refined with anisotropic thermal parameters and hydrogen atoms were placed in fixed, calculated positions using a riding model (C-H $0.96 \AA$ ). Pertinent experimental data are listed in Tables 1,2.

\section{Supplementary Materials}

Crystallographic data have been deposited with the Cambridge crystallographic Data Centre: CCDC 689661 (5d) and 689662 (8). These data can be obtained free of charge at www.ccdc.cam.ac.uk/conts/retrieving.html or from the Cambridge Crystallographic Data Centre, 12 Union Road, Cambridge CB2 1EZ, UK, fax: (internat.) +44 1223336 033, e-mail: deposit@ccdc.cam.ac.uk.

\section{Acknowledgements}

We thank the Ukrainian State Fund of Fundamental Research for financial support (grant F25.3/049) and the Robert A. Welch Foundation F0003 for financial support of the X-ray diffraction studies.

\section{References}

1. Dias, H. V. R.; Jin, W. Tetrahedron Lett. 1994, 35, 1365.

2. (a) Herrmann, W. A.; Kocher, C.; Goossen, L. J.; Artus, G. R. J. Chem. Eur. J. 1996, 2, 1627.

(b) Herrmann, W. A.; Elison, M.; Fischer, J.; Kocher, C.; Artus, G. R. J. Chem. Eur. J. 1996, 2,772 .

3. Caballero, A.; Diez-Barra, E.; Jalon, F. A.; Merino, S.; Tejeda, J. J. Organomet. Chem. 2001, 617/618, 395.

4. Danopoulos, A. A.; Winston, S.; Motherwell, W. B. Chem. Commun. 2002, 1376. 
5. Korotkikh, N. I.; Shvaika, O. P.; Rayenko, G. F.; Kiselyov, A. V.; Knishevitsky, A. V.; Cowley, A. H.; Jones, J. N.; Macdonald, C. L. B. Arkivoc 2005, 10.

6. Knishevitsky, A. V.; Korotkikh, N. I.; Cowley, A. H.; Moore, J. A.; Pekhtereva, T. M.; Shvaika, O. P. J. Organomet. Chem. 2008, 693, 1405.

7. Korotkikh, N. I.; Kiselyov, A. V.; Knishevitsky, A. V.; Rayenko, G. F.; Pekhtereva, T. M.; Shvaika, O. P. Chem. Heterocycl. Comp. (Latvia) 2005, 1026.

8. Shvaika, O. P.; Mnatsakanova, T. R. J. Gen. Chem. (Russia) 1964, 2061.

9. Korotkikh, N. I.; Rayenko, G. F.; Kiselyov, A.V.; Knishevitsky, A.V.; Shvaika, O. P.; Cowley, A. H.; Jones, J. N.; Macdonald, C. L. B. In Selected Methods for Synthesis and Modification of Heterocycles, Iridium-Press: Moscow, 2002; Vol. 1, 279.

10. Lantvoev V. M. Contemporary Problems of Organic Chemistry, LSU: Leningrad, 1978, Vol. 6, p 94 (in Russian).

11. (a) Arduengo, III, A. J.; Harlow, R. L.; Kline, M. J. Am. Chem. Soc. 1991, 113, 361. (b) Arduengo, III, A. J.; Dias, H. V. R.; Harlow, R. L.; Kline, M. J. Am. Chem. Soc. 1992, 114, 5530.

12. Korotkikh, N. I.; Rayenko, G. F.; Shvaika, O. P. Rep. Ukr. Acad. Sci. 2000, 135.

13. Korotkikh, N. I.; Kiselyov, A. V.; Rayenko, G. F.; Oliinik, N. M.; Shvaika, O. P. Rep. Ukr. Acad. Sci. 2003, 142.

14. Korotkikh, N. I.; Rayenko, G. F.; Shvaika, O. P.; Pekhtereva, T. M.; Cowley A. H.; Jones J. N.; Macdonald, C. L. B. J. Org. Chem. 2003, 68, 5762.

15. (a) Enders, D.; Breuer, K.; Raabe, G.; Runsink, J.; Teles, J. H.; Melder, J.-P.; Ebel, K.; Brode, S. Angew. Chem. Int. Ed. 1995, 34, 1021. (b) Enders, D.; Breuer, K.; Kallfass, U.; Balensiefer, T. Synthesis 2003, 1292.

16. Taton, T. A.; Chen, P. Angew. Chem. Int. Ed. 1996, 35, 1011.

17. Korotkikh, N. I.; Glinyanaya, N. V.; Cowley, A. H.; Moore, J. A.; Knishevitsky, A. V.; Pekhtereva, T. M.; Shvaika, O. P. Arkivoc 2007, 156.

18. Remi, H. Lehrbuch der Organishen Chemie, Academische Verlagsgesellschaft: Leipzig, (Rus. edit.), 1961; Vol. 2, p832.

19. Herrmann, W. A.; Ofele, K.; Preysing, D. V.; Herdtweck, E. J. Organomet. Chem. 2003, 684, 235.

20. Schneider, N.; Cersar, V.; Bellemin-Laponnaz, S.; Gade, L. H. J. Organomet. Chem. 2005, $690,5556$.

21. Sheldrick, G. M. SHELL-PC Version 5.03, Siemens Analytical X-ray 515 Instruments, Inc., Madison, WI, USA, 1994. 